\title{
Pancreatitis in rheumatoid arthritis and the role of systemic vasculitis of autoimmune origin in the pathogenesis of pancreatitis - A postmortem clinicopathologic study of I6I patients
}

\begin{abstract}
Aim: The aim of this study was to determine the prevalence of acute liponecrotic (aLnP), acute relapsing liponecrotic (aRelLnP), and chronic liponecrotic pancreatitis (chrLnP) in $\mathrm{RA}$, and analyze the possible role of systemic vasculitis of autoimmune origin (A-SV) in the pathogenesis of liponecrotic pancreatitis $(\mathrm{LnP})$, furthermore to assess the predictive clinical laboratory parameters for $\mathrm{LnP}$ and A-SV.
\end{abstract}

Patients and methods: At the National Institute of Rheumatology 9475 patients died between 1969 and 1992; among them 161 with RA and all of them were autopsied. RA was confirmed clinically according to the criteria of the American College of Rheumatology (ACR). Tissue samples of pancreas were available in 118 of 161 patients. Prevalence and histological patterns of pancreatitis were determined at autopsy and characterized histologically. Demographics and laboratory parameters of different patient cohorts were compared with the Student (Welch) t-probe. The relationship between aLnP or aRelLnP and A-SV, furthermore between chrRelP and A-SV were analyzed by Pearson's chi-squared $\left(\chi^{2}\right)$ test.

Results: Pancreatitis with multiple liponecrotic foci (LnP) were found in $15(12.71 \%)$ of 118 patients; aLnP existed in 8 (53.33\%), aRelLnP in 4 (26.67\%), and liponecrotic foci in combination with chronic fibrotic pancreatitis (chrLnP) in $3(20.0 \%)$ of these 15 patients. A-SV complicated RA in 25 (21.18\%) of 118 patients, and the pancreatic blood vessels were involved in $9(36.00 \%)$ of these 25 patients; in $16(64.00 \%)$ of 25 patients vasculitis was not found in the pancreas. The RA started later in female patients, complicated or associated with $\mathrm{LnP}$, (55.4 years versus 50.15 at onset of disease), and led notably earlier to death (within 7.44 years versus 14.93); the difference of latter was significant $(\mathrm{p}<0.0396$ ). The mean age of RA female patients, complicated by A-SV was significantly higher at onset of disease ( 60.57 years versus $48.33 ; \mathrm{p}<0.0007)$, and the female patients with A-SV died significantly earlier (within 10.0 years versus $15.09 ; \mathrm{p}<0.045$ ). The link between A-SV and LnP was positive and significant (association's coefficient $=0.7539, \chi^{2}=8.8418$, $\mathrm{p}<0.003$ ), which was resulted by the very strong positive correlation between A-SV and aRelLnP $\left(\chi^{2}=17.6949, \mathrm{p}<0.0000\right)$. The relationship between A-SV and aLnP (association's coefficient negative, $\left(\chi^{2}=0.0231, \mathrm{p}<0.88\right)$ or A-SV and chrLnP (association's coefficient negative, $\chi^{2}=0.3570, \mathrm{p}<0.55$ ) was not significant.

Discussion and conclusion: The risk of $\mathrm{LnP}$ or A-SV is higher in elderly female RA patients, and their chance of survival is lower than in males, or compared with RA patients who did not have LnP or A-SV. A-SV, as a basic complication of RA, should be regarded an important vasculogenic factor in the pathogenesis of aRelLnP, which may be regarded as a special manifestation of autoimmune pancreatitis or a vasculogenic entity in RA. The clinical significance of laboratory parameters (elevated erythrocyte sedimentation rate, increased C-reactive protein level, anemia, thrombocytosis, hypoalbuminemia, and a positive rheumatoid factor) mentioned in the literature for diagnosis of A-SV were confirmed by our study and we found further differences regarding the Latex fication, BUN and creatinin levels. Unfortunatelly they are not specific for vasculitis and do not predict vasculitis. They are related to the basic activity of RA, to renal complications of RA or to the actual intensity of inflammatory processes of the disease. In cases of suspected vasculitis the biopsy remains the gold standard.

Elevated diastase values were characteristics for $\mathrm{LnP}$ in agreement with the literature. The levels of GGT showed significant differences between patient cohorts with and without $\mathrm{LnP}$ or compared to the total population of RA patients. The study is recommended to general physicians, who may meet patients with autoimmune disorders or are interested in autoimmune diseases.

Keywords: Rheumatoid arthritis, pancreatitis, systemic vasculitis of autoimmune origin, laboratory parameters
Volume 10 Issue I - 2019

\section{Miklós Bély, Ágnes Apáthy²}

'Department of Pathology, Hospital of the Order of the Brothers of Saint John of God, Hungary ${ }^{2}$ Department of Rheumatology - St. Margaret Clinic, Budapest, Hungary

Correspondence: Miklós Bély M.D., Ph.D., D.Sc. Acad. Sci. Hung, Hospital of the Order of the Brothers of Saint John of God, Budapest, Hungary, Department of Pathology, H- 1027 Budapest, Frankel L. 17-19, Hungary Tel (36I) 438 849I, (06-30) 2194I42, Email dr.bely.miklos@gmail.hu

Received: October 29, 2018 | Published: January 25, 2019 
Abbreviations: RA, rheumatoid arthritis; ARA, american college of rheumatology, TIGAR-O, (Toxic-Metabolic, Idiopathic, Genetic, Autoimmune, Recurrent and Severe Acute Pancreatitis, Obstructive) classification system; LnP, liponecrotic pancreatitis; aLnP, acute liponecrotic pancreatitis; aRelLnP, acute relapsing liponecrotic pancreatitis; chrP, chronic pancreatitis; chrRelP, chronic relapsing pancreatitis; chrLnP, chronic liponecrotis pancreatitis; A-SV, systemic vasculitis of autoimmune origin; H-E, hematoxylineosin staining; ESR, erythrocyte sedimentation rate; $\mathrm{CRP}-\mathrm{C}$, reactive protein; BUN, blood urea nitrogen; RBC, red blood cells; WBC, white blood cells; LDH, lactate dehydrogenase; GPT, glutamic- pyruvictransaminase; GGT, gamma-glutamyl-transpeptidase; SD, standard deviation, AAa, systemic AA amyloidosis

\section{Introduction}

The prevalence of pancreatitis is higher in rheumatoid arthritis (RA) than in the general population. ${ }^{1}$ According to the Mayo Clinic staff the most common conditions associated with pancreatitis are "alcoholism, gallstones, abdominal surgery, certain medications, cigarette smoking, cystic fibrosis, family history of pancreatitis, hypercalcemia, which may be caused by an overactive parathyroid gland (hyperparathyroidism), high triglyceride levels in the blood (hypertriglyceridemia), infection, injury to the abdomen, pancreatic cancer or endoscopic retrograde cholangiopancreatography (ERCP)", confirmed by others. ${ }^{3-5}$ Sometimes the cause for pancreatitis cannot be found. ${ }^{2,6-8}$

The TIGAR-O classification system categorizes known causes and risk factors that may interact and produce acute, acute recurrent or chronic pancreatitis. ${ }^{9,10}$ Acute, acute recurrent and chronic pancreatitis represent a disease continuum. ${ }^{10}$ The progression of acute pancreatitis to a chronic one may be evident. ${ }^{11,12}$ The initial and most characteristic feature of acute liponecrotic pancreatitis $(\mathrm{aLnP})$ is acinar cell necrosis followed by a more or less pronounced inflammatory reaction, and later glandular atrophy and fibrosis. ${ }^{13,14}$ Recurrent harmful effects (repeatedly acting risk factors) may result in acute relapsing liponecrotic (aRelLnP) or chronic liponecrotic pancreatitis (chrLnP), depending on the stage of progression. ${ }^{13,14}$

The aim of this study was to determine the prevalence of acute liponecrotic (aLnP), acute relapsing liponecrotic (aRelLnP), and chronic liponecrotic pancreatitis (chrLnP) in RA, and analyze the possible role of systemic vasculitis of autoimmune origin (A-SV) in the pathogenesis of liponecrotic pancreatitis $(\mathrm{LnP})$, furthermore to assess the predictive clinical laboratory parameters for LnP and A-SV. Our study focused on the relationship of $\mathrm{LnP}$ and A-SV; risk factors for pancreatitis such as alcohol consumption, smoking, drugs, body weight, family history etc. were not evaluated.

\section{Patients and methods}

At the National Institute of Rheumatology 9475 patients died between 1969 and 1992; among them 161 with RA and all of them were autopsied. ${ }^{15}$ RA was confirmed clinically according to the criteria of the American College of Rheumatology (ACR). ${ }^{16}$

Tissue samples of pancreas were available or sutable for histologic evaluation without autolytic demage in 118 of 161 patients. Prevalence and histological patterns of pancreatitis were determined at autopsy and characterized histologically. ${ }^{13,14}$ The presence of A-SV was confirmed by a detailed review of extensive histological material in agreement with the recommendations of the Consensus Conference (2013), ${ }^{17}$ Scott et al., ${ }^{18}$ and Schilling and Fassbender. ${ }^{19}$ From each patient a total of 50-100 tissue blocks of 12 organs (heart, lung, liver, spleen, kidneys, pancreas, gastrointestinal tract, adrenal glands, skeletal muscle, peripheral nerve, skin and brain) were studied microscopically.

The correlations were determined by the Student (Welch) t-probe, ${ }^{20}$ comparing the age, sex of patients, onset of RA, duration of disease, and laboratory parameters (Latex, Waaler-Roose values, ESR, CRP, albumin/globulin ratio, serum electrophoresis (albumin, alpha-1-globulin, alpha-2-globulin, beta-globulin, gamma-globulin), $\mathrm{RBC}$, hemoglobin, WBC, systolic and diastolic blood pressure, blood urea nitrogen (BUN), serum creatinine, serum potassium and sodium values, urine specific gravity, proteinuria, urine sediment (RBC, WBC), serum bilirubin, LDH, GPT, GGT, blood sugar, and diastase values) at the last hospitalization: with and without $\mathrm{LnP}$ or A-SV. The rerelationship between aLnP or aRelLnP and A-SV, furthermore between chrRelP and A-SV were analyzed by Pearson's chi-squared $\left(\chi^{2}\right)$ test. $^{20}$

\section{Glossary of definitions}

\section{Histologic patterns of pancreatitis ${ }^{13,14}$}

Liponecrotic pancreatitis (LnP) -multiple acinar liponecrotic foci, with or without inflammatory reaction, with or without hemorrhages

Acute liponecrotic pancreatitis (aLnP) - acinar liponecrotic foci usually in the same stage and similar size of necrosis, with or without inflammatory reaction, with or without hemorrhages

Acute relapsing liponecrotic pancreatitis (aRelLnP) - acinar liponecrotic foci in different stage and size of necrosis, with or without inflammatory reaction, hemorrhages, calcification (saponification) or liquefaction (pseudocyst formation)

Chronic pancreatitis (chrP) - multifocal or diffuse fibrotic interstitial pancreatitis with more or less explicit (pronounced) glandular atrophy, with or without ductal changes: plugges (concentrated secretum of exocrine glands), ductal dilatation (ductectasia), ductal proliferation, and metaplasia

Chronicrelapsing pancreatitis (chrRelP) - focal accentuated diffuse fibrotic interstitial pancreatitis usually with pronounced glandular atrophy and ductal changes

Chronic liponecrotic pancreatitis (chrLnP) - liponecrotic foci in combination with histological characteristics of chrP or chrRelP

Edematous inflammatory pancreatitis or "serous" infection associated pancreatitis (eIP) - usually a mild diffuse edematous inflammatory interstitial pancreatitis without acinar cell necrosis or hemorrhages

The prevalence of chrP, chrRelP and eIP were not evaluated in this study

"Prevalence" of vasculitis - concerns the presence of inflammatory infiltration and structural changes in blood vessels of different calibers

Systemic vasculitis of autoimmune origin (A-SV) - A-SV was defined as one of the basic manifestations of RA, ${ }^{15}$ excluding other causes of vasculitis, like hypertension, diabetes mellitus, tumors, septic infections, etc. 
Size of blood vessels ${ }^{21}$ in tissue samples with branches of splenic artery, upper and lower gastroduodenal arteries

Arteriole (a) - no internal or external elastic membrane, $<500$ micrometers in diameter

Small artery (A) - only internal elastic membrane present, vessels 500-1000 micrometers in diameter

Medium size artery (AA) - internal and external elastic membrane are present - vessel $>1000$ micrometers in diameter

Venule $(\mathrm{v})$, small vein $(\mathrm{V})$, medium size vein $(\mathrm{VV})$-accompanying (a), (A) or (AA)

\section{Results}

Multiple liponecrotic foci ( $\mathrm{LnP})$ were found in $15(12.71 \%)$ of 118 patients; aLnP existed in 8 (53.33\%), aRelLnP in 4 (26.67\%), and liponecrotic foci in combination with chronic fibrotic pancreatitis (chrLnP) in $3(20.0 \%)$ of these 15 patients.

A-SV complicated RA in $25(21.18 \%)$ of 118 patients, and the pancreatic blood vessels (branches of splenic artery, upper and lower gastroduodenal arteries) were involved in $9(36.00 \%)$ of these 25 patients \& $16(64.00 \%)$ of 25 patients vasculitis was not found in the pancreas.

Demographics, onset and duration of disease associated with or complicated by LnP and A-SV are summarized in Table 1 and Figure

Table I Sex, mean age with SD, range, onset and disease duration (in years) of RA patients with or without $\operatorname{LnP}(n=15)$ and $A-S V(n=25)$ of II8 RA patients

\begin{tabular}{|c|c|c|c|c|c|}
\hline Sex & $\begin{array}{l}\text { Number of } \\
\text { autopsies }\end{array}$ & $\begin{array}{l}\text { Mean age in years } \\
\text { at death } \pm S D\end{array}$ & $\begin{array}{l}\text { Range(in } \\
\text { years) }\end{array}$ & $\begin{array}{l}\text { Mean age at onset } \\
\text { of disease } \pm \text { SD }\end{array}$ & $\begin{array}{l}\text { Disease duration (in } \\
\text { years) mean } \pm \text { SD }\end{array}$ \\
\hline RA patients & 161 & $65.32 \pm 12.95$ & $16-88$ & $50.83 \pm 16.96$ & $|4.43 \pm| 0.5 \mid$ \\
\hline Female & 116 & $64.95 \pm 11.79$ & $16-87$ & $50.19 \pm 15.70$ & $14.79 \pm 10.65$ \\
\hline Male & 45 & $66.29 \pm 15.50$ & $19-88$ & $52.57 \pm 19.88$ & $13.46 \pm 10.08$ \\
\hline RA pts with pancreas & 118 of 161 & $64.97 \pm 12.84$ & $16-88$ & $51.44 \pm 16.80$ & $|3.84 \pm| 0.40$ \\
\hline Female & 80 & $64.4 I \pm 11.95$ & $16-87$ & $50.75 \pm 15.03$ & $13.84 \pm 10.43$ \\
\hline Male & 38 & $66.16 \pm 14.48$ & $19-88$ & $53.03 \pm 20.20$ & $|3.29 \pm| 0.3 \mid$ \\
\hline With LnP & 15 of 118 & $65.13 \pm 14.12$ & $32-87$ & $56.63 \pm 13.03$ & $9.79 \pm 8.19$ \\
\hline Female & 10 & $65.10 \pm 11.43$ & $5 \mathrm{I}-87$ & $55.44 \pm 12.72$ & $7.44 \pm 7.64$ \\
\hline Male & 5 & $65.20 \pm 18.35$ & $32-82$ & $59.00 \pm 13.32$ & $14.50 \pm 7.16$ \\
\hline Without LnP & 103 of 118 & $64.95 \pm 12.65$ & $16-88$ & $50.75 \pm 17.13$ & $|4.38 \pm| 0.54$ \\
\hline Female & 70 & $64.3| \pm| 2.01$ & $16-84$ & $50.15 \pm 15.19$ & $14.93 \pm 10.43$ \\
\hline Male & 33 & $66.27 \pm 13.80$ & $19-88$ & $52.15 \pm 20.88$ & $13.11 \pm 10.68$ \\
\hline With A-SV & 25 of II 8 & $66.80 \pm 11.64$ & $32-83$ & $56.54 \pm 15.56$ & II.7I士II.0I \\
\hline Female & 14 & $66.93 \pm 12.48$ & $32-82$ & $60.57 \pm 9.17$ & $10.00 \pm 7.00$ \\
\hline Male & 11 & $66.55 \pm 10.44$ & $53-83$ & $50.90 \pm 20.22$ & $14.10 \pm 14.58$ \\
\hline Without A-SV & 93 of II 8 & $64.48 \pm \mid 3.11$ & $16-88$ & $49.87 \pm 16.86$ & $|4.50 \pm| 0.11$ \\
\hline Female & 66 & $63.88 \pm 11.76$ & $16-87$ & $48.33 \pm 15.21$ & $15.09 \pm 10.88$ \\
\hline Male & 27 & $65.96 \pm 15.83$ & 19-88 & $54.05 \pm 20.11$ & $12.90 \pm 7.42$ \\
\hline
\end{tabular}

\section{Glossary to Table I}

RA, rheumatoid arthritis; LnP, liponecrotic pancreatitis;A-SV, systemic vasculitis of autoimmune origin

SD, standard deviation

There was no significant difference in survival time, onset or duration of RA between patient cohort's of 161 and 118 patients $(\mathrm{p}<$ $0.82, \mathrm{p}<0.78, \mathrm{p}<0.67)$, neither between female $(\mathrm{p}<0.76, \mathrm{p}<0.81$, $\mathrm{p}<0.67)$ nor between male $(\mathrm{p}<0.97, \mathrm{p}<0.93, \mathrm{p}<0.95)$. Comparing the age, sex, onset of RA, and duration of disease at the time of death there was no significant difference in survival time, onset and duration of disease between patients with LnP and without LnP or with A-SV and without A-SV of 118 RA patients (Table 1 and Figure 1). 


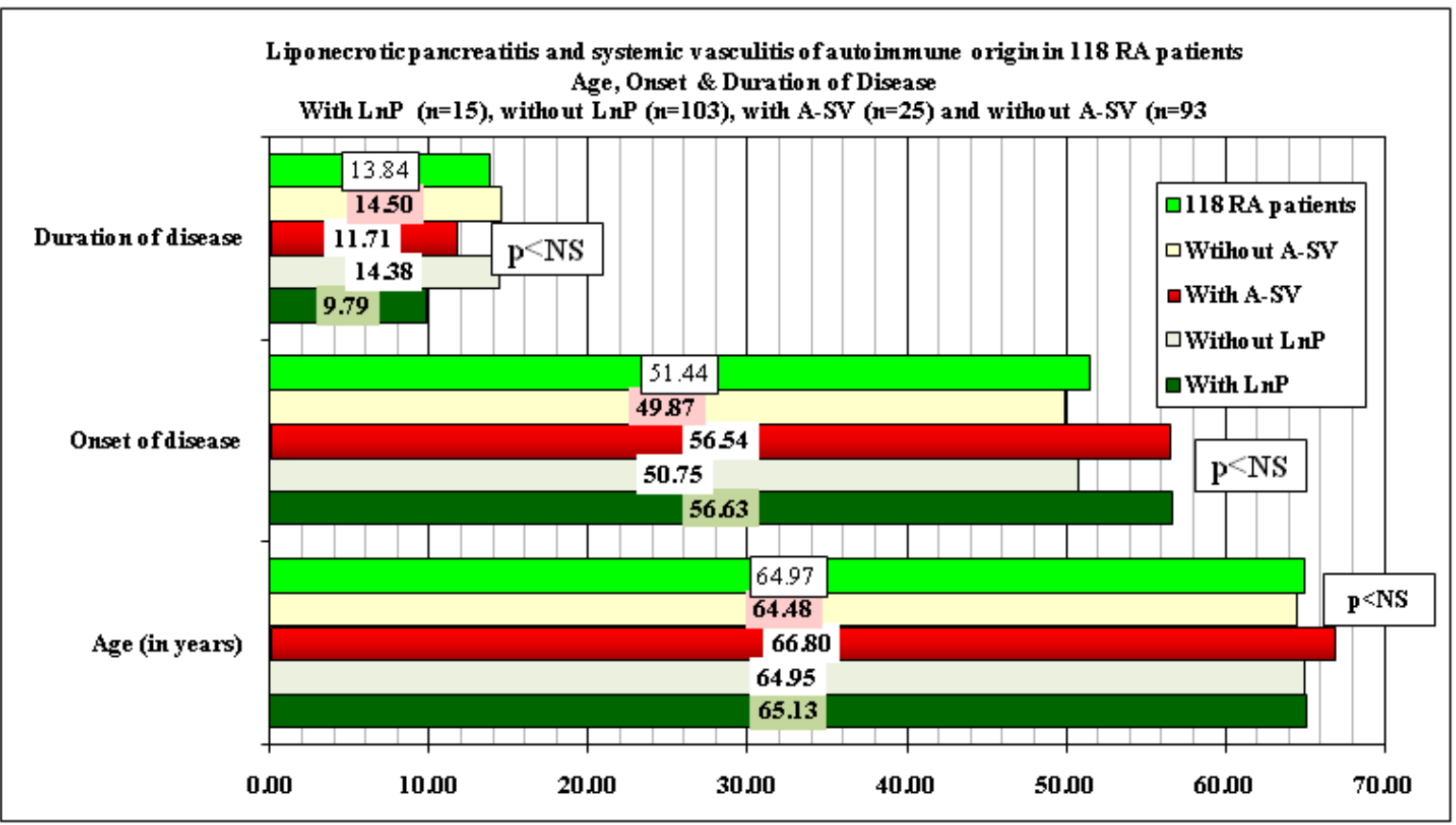

Figure I Comparing the age, sex, onset of RA, and duration of disease at the time of death there was no significant difference in survival time, onset and duration of disease of 118 patients with LnP and without LnP or with A-SV and without A-SV.

Demographics, onset and duration of RA in patients with LnP $(\mathrm{n}=15)$ and without $\mathrm{LnP}(\mathrm{n}=103)$ or with A-SV $(\mathrm{n}=25)$ and without A-SV ( $n=94)$ of 118 RA patients (Figure 1).

RA started later in female patients, complicated by or associated with LnP, (55.4 years versus 50.15 at onset of disease), and led notably earlier to death (within 7.44 years versus 14.93); the difference of latter was significant $(\mathrm{p}<0.0396)$. The mean age of RA female patients, complicated by A-SV was significantly higher at onset of disease (60.57 years versus $48.33 ; \mathrm{p}<0.0007)$, and the female patients with A-SV died significantly earlier (within 10.0 years versus 15.09 ; $\mathrm{p}<0.0446$ ) (Table 1) (Table 2)(Figures $2.1 \& 2.2$ ).

Table 2 The statistical correlations (" $\mathrm{P}$ " values of significance) between female and male RA patients with and without LnP or A-SV

\begin{tabular}{|c|c|c|c|}
\hline RA patients $n=161$ & Age & Onset of disease & Disease duration \\
\hline RA pts. $n=|6|$ versus pts with pancreas $n=|| 8$ & $\mathrm{P}<0.82$ & $\mathrm{p}<0.78$ & $\mathrm{p}<0.67$ \\
\hline Female $n=116$ versus $n=80$ & $\mathrm{P}<0.76$ & $\mathrm{P}<0.82$ & $\mathrm{P}<0.67$ \\
\hline Male $n=45$ versus $n=38$ & $\mathrm{P}<0.97$ & $\mathrm{p}<0.93$ & $\mathrm{p}<0.95$ \\
\hline RA pts. $n=\mid 18$ versus $R A$ with $\operatorname{LnP} n=15$ & $\mathrm{p}<0.97$ & $\mathrm{p}<0.24$ & $p<0.15$ \\
\hline Female $n=80$ versus $n=10$ & $\mathrm{P}<0.87$ & $\mathrm{p}<0.38$ & $\mathrm{P}<0.064$ \\
\hline Male $n=38$ versus $n=5$ & $\mathrm{P}<0.93$ & $\mathrm{P}<0.52$ & $\mathrm{P}<0.80$ \\
\hline with $\operatorname{LnP} n=15$ versus without $\operatorname{LnP} n=103$ & $\mathrm{P}<0.96$ & $\mathrm{P}<0.19$ & $\mathrm{P}<0.1 \mathrm{I}$ \\
\hline Female $n=10$ versus $n=70$ & $\mathrm{P}<0.85$ & $\mathrm{P}<0.33$ & $p<0.0396$ \\
\hline Male $n=5$ versus $n=33$ & $\mathrm{P}<0.91$ & $\mathrm{P}<0.47$ & $\mathrm{p}<0.78$ \\
\hline RA pts. $n=118$ versus $R A$ with $\mathbf{A}-\mathbf{S V} n=25$ & $\mathrm{P}<0.50$ & $\mathrm{P}<0.17$ & $\mathrm{p}<0.40$ \\
\hline Female $n=80$ versus $n=14$ & $\mathrm{P}<0.5$ I & $\mathrm{p}<0.004$ & $\mathrm{p}<0.09$ \\
\hline Male $n=38$ versus $n=11$ & $\mathrm{P}<0.92$ & $\mathrm{P}<0.79$ & $\mathrm{p}<0.88$ \\
\hline with A-SV $n=25$ versus without A-SV $n=93$ & $\mathrm{P}<0.40$ & $\mathrm{P}<0.08$ & $\mathrm{P}<0.28$ \\
\hline Female $n=14$ versus $n=66$ & $\mathrm{p}<0.43$ & $p<0.0007$ & $\mathrm{p}<0.0446$ \\
\hline Male $n=1 \mid$ versus $n=27$ & $p<0.90$ & $\mathrm{P}<0.70$ & $\mathrm{P}<0.82$ \\
\hline
\end{tabular}

\section{Glossary to Table 2}

RA, rheumatoid arthritis; LnP, liponecrotic pancreatitis;A-SV, systemic vasculitis of autoimmune origin 


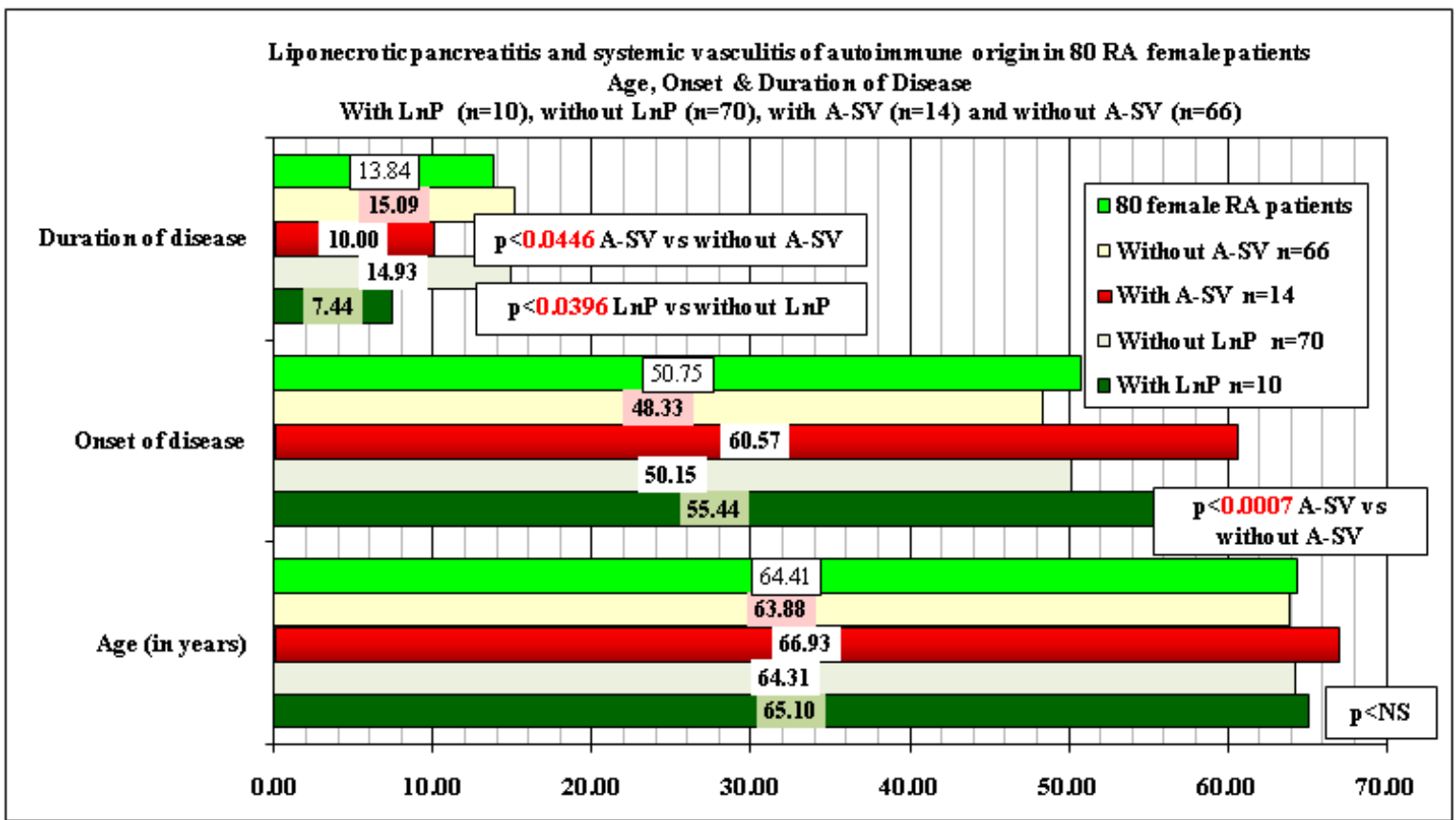

Figure 2.I Demographics, onset and duration of female RA in patients $(n=80)$ with $\operatorname{LnP}(n=10)$ and without $\operatorname{LnP}(n=70)$ or with $A-S V(n=14)$ and without $A-S V$ $(n=66)$ of 118 RA patients.

RA started later in female patients with LnP, (55.4 years versus 50.15 at onset of disease), and the patients died earlier (within 7.44 years versus I4.93); the difference of latter was significant $(p<0.0396)$.

The mean age of RA female patients, complicated by A-SV was significantly higher at onset of disease $(60.57$ years versus 48.33 ; $\mathbf{p}<0.0007)$, and the female patients with A-SV died significantly earlier (within 10.0 years versus 15.09 ; $\mathbf{p}<\mathbf{0 . 0 4 4 6}$ ).

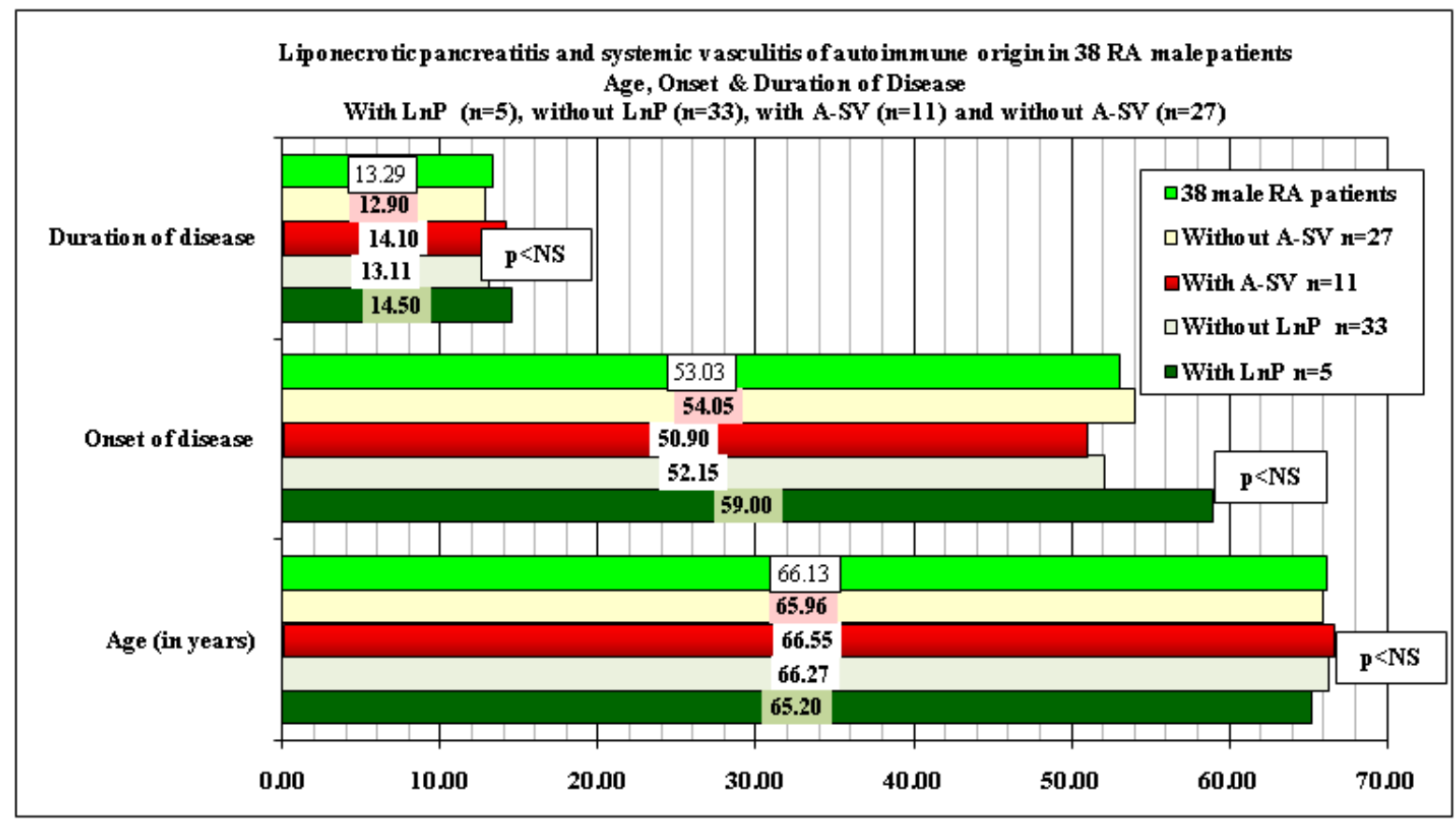

Figure 2.2 Demographics, onset and duration of male RA in patients $(n=38)$ with $\operatorname{LnP}(n=5)$ and without $\operatorname{LnP}(n=33)$ or with $A-S V(n=I I)$ and without $A-S V$ $(n=28)$ of 1 I 8 RA patients.

There was no significant difference in survival time, onset or duration of RA between patient cohorts of 38 male with or without LnP and with or without A-SV.

Comparing the age, sex, onset of RA, and duration of disease at the time of death there was no significant difference between female $(\mathrm{p}<0.85, \mathrm{p}<0.33, \mathrm{p}<0.039)$ and male $(\mathrm{p}<0.91$, $\mathrm{p}<0.47, \mathrm{p}<0.78)$ RA patients with $\operatorname{LnP}(\mathrm{p}<0.96, \mathrm{p}<0.19, \mathrm{p}<0.11)$ and without LnP, except duration of RA of female patients; and between female $(\mathrm{p}<0.43, \mathrm{p}<0.0007, \mathrm{p}<0.0446)$ and male $(\mathrm{p}$ 
$<0.90, \mathrm{p}<0.70, \mathrm{p}<0.82)$ RA patients with $\mathrm{A}-\mathrm{SV}(\mathrm{p}<0.40, \mathrm{p}<0.08$ $\mathrm{p}<0.28$ ) and without A-SV, except onset and duration of RA of female patients (Table 2).
Mean values of pertinent clinical laboratory parameters with and without A-SV or in total population of RA patients at death with " $p$ "values of correlation are shown in Table 3 and Figures $3.1 \& 3.2$.

Table 3 The mean values of clinical laboratory parameters with and without A-SV or in total population of RA patients at death and the " $p$ " values of significance.

\begin{tabular}{|c|c|c|c|c|c|}
\hline $\begin{array}{l}\text { Mean values of laboratory } \\
\text { parameters } \pm S D\end{array}$ & $\begin{array}{l}\text { With A-SV } \\
n=25\end{array}$ & $\begin{array}{l}\text { Without A-SV } \\
n=93\end{array}$ & $\begin{array}{l}\text { Total } n \text { of pts } \\
n=1 \mid 8\end{array}$ & Normal range & $\begin{array}{l}\mathrm{p}<25 \text { vs } 93 \text { and } \\
\mathrm{p}<25 \text { vs I I } 8 \text { RA pts }\end{array}$ \\
\hline Latex-I-4+ & $3.82 \pm 0.49$ & $3.14 \pm 1.23$ & $3.30 \pm 1.14$ & $0+$ & $0.0003 ; 0.0014$ \\
\hline $\mathrm{BUN}-\mathrm{mmol} / \mathrm{l}$ & $9.14 \pm 3.25$ & $|3.4| \pm|2.4|$ & $12.37 \pm 11.06$ & $2.00-8.90 \mathrm{mmol} / \mathrm{l}$ & $0.011 ; 0.018$ \\
\hline Creatinin- $\mu \mathrm{mol} / / \mathrm{l}$ & $81.27 \pm 33.02$ & $13 \mid .42 \pm 102.50$ & $119.96 \pm 93.809$ & $62-106 \mu \mathrm{mol} / \mathrm{l}$ & $0.0033 ; 0.008$ \\
\hline $\mathrm{RBC}-\mathrm{T} / \mathrm{I}$ & $4.05 \pm 0.538$ & $3.68 \pm 0.711$ & $3.78 \pm 0.687$ & $4.50-5.90 \mathrm{~T} / \mathrm{I}$ & $0.022 ; 0.073$ \\
\hline $\mathrm{ESR}-\mathrm{mm} / \mathrm{h}$ & $84.63 \pm 29.97$ & $80.72 \pm 36.3$ & $81.66 \pm 34.92$ & $\leq 15-20 \mathrm{~mm} / \mathrm{h}$ & $0.607,0.68 I-N S$ \\
\hline CRP-mg/l & $361.89 \pm 649.5$ & $404.67 \pm 994.7$ & $371.32 \pm 739.8$ & $0.00-5.00 \mathrm{mg} / \mathrm{l}$ & $0.88 \mathrm{I}, 0.907-\mathrm{NS}$ \\
\hline albumine-g/l & $29.87 \pm 5.18$ & $29.22 \pm 6.175$ & $29.38 \pm 5.95$ & $35-50 \mathrm{~g} / \mathrm{l}$ & $0.703,0.764-N S$ \\
\hline Waaler-Rose titre & $501.0 \pm 962.4$ & $435.05 \pm 1033$ & $456.32 \pm 1011$ & $\mathrm{I}: 160$ & $0.81 \mathrm{I}, 0.862-N S$ \\
\hline
\end{tabular}

Glossary to Table 3 (Significantly different links are in red)

RA, rheumatoid arthritis;A-SV, systemic vasculitis of autoimmune origin; ESR, erythrocyte sedimentation rate

CRP-C, reactive protein; SD, standard deviation

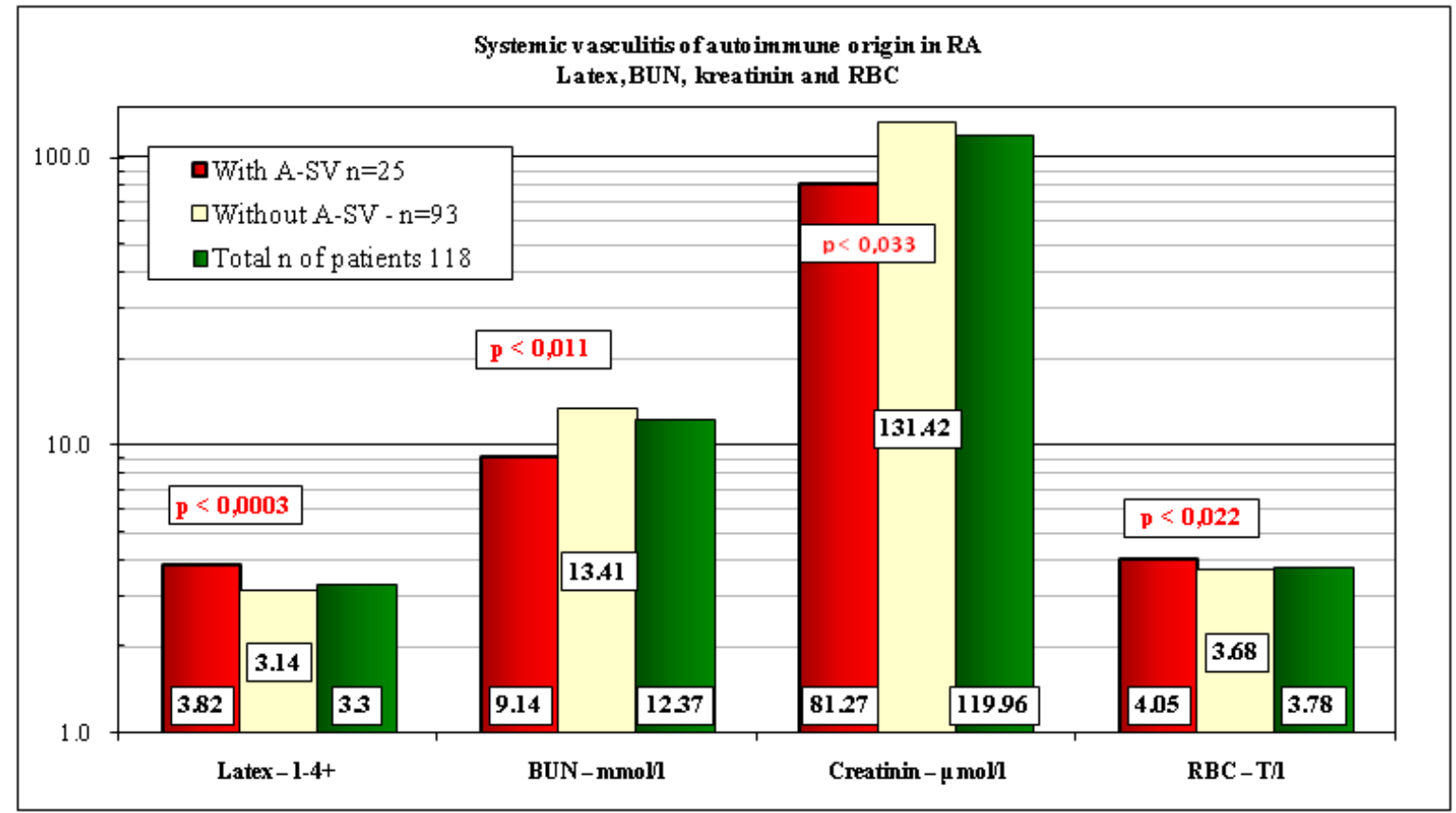

Figure 3.I Significant differences in laboratory parameters with and without A-SV or of total number of RA patients. The "p" values of correlation represent the differences between with and without A-SV of RA patients.

The patients with A-SV had significantly higher values of Latex fixation compared those to the patients without A-SV, and higher levels of serum carbamide, and creatinin in comparison to the normal laboratory range.

The RA patients were anemic in all groups in comparison to the normal laboratory range of RBCs (Table 3 \& Figure 3.1).

The mean values of clinical-laboratory parameters with clinical significance (ESR, CRP, albumin, and rheuma facor), were elevated with and without A-SV or in total number of RA patients as well, but these differences were not significant in our patient cohorts (Table 3 \& Figure 3.1)
The pertinent clinical laboratory parameters with and without LnP or in total number of RA patients at death are shown in Table 4 \& Figure 4 . The values of lipase values were determined occasionally at death; not mentioned in Table 4 and Figure 4.

The laboratory data of patients with LnP revealed significantly lower levels of serum GGT $(\mathrm{p}<0.00000086)$ in comparison without LnP or compared to the total population of RA patients ( $p<$ 0.0000014). The serum blood diastase values were higher with LnP $(1842.50 \pm 2848.74)$ than in patients without LnP $(293.79 \pm 326.16)$ or in total number of RA patients, but these differences were not signiificant (Table 4). 


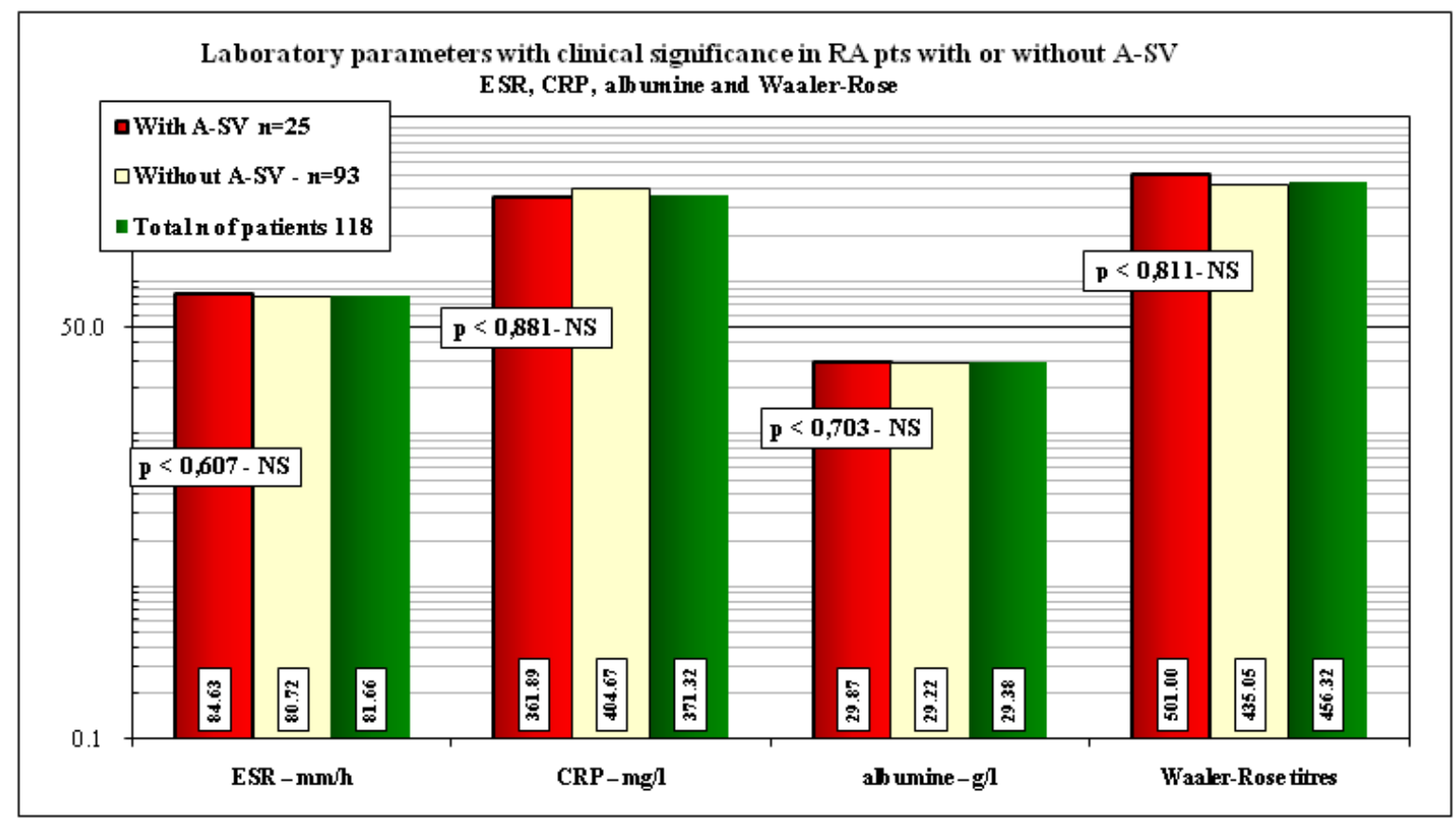

Figure 3.2 Elevated (not significant) laboratory parameters with and without A-SV or of total population of RA patients. The " $p$ " values of correlation represent the differences between with and without A-SV of RA patients.

Table 4 The clinical laboratory parameters with and without LnP or in total number of RA patients at death and and the "p" values of significance.

\begin{tabular}{|c|c|c|c|c|c|}
\hline $\begin{array}{l}\text { Mean values of laboratory } \\
\text { parameters } \pm \text { SD }\end{array}$ & With LnP n=15 & $\begin{array}{l}\text { Without LnP - } \\
n=103\end{array}$ & $\begin{array}{l}\text { Total } n \text { of patients } \\
\text { I } 18\end{array}$ & Normal range & $\begin{array}{l}\text { p<vs } 103 \text { and vs. } \\
\text { II } 8 \text { RA pts }\end{array}$ \\
\hline GGT U/I & $14.20 \pm 5.15$ & $69.38 \pm 64.3$ & $64.08 \pm 63.28$ & II-50 U/I & $\begin{array}{l}0.00000086 \\
0.0000014\end{array}$ \\
\hline Serum diastase U/I & $1842.50 \pm 2848.74$ & $293.79 \pm 326.16$ & $563.13 \pm 1357.88$ & $28-100 \mathrm{U} / \mathrm{I}$ & $\begin{array}{l}0.416-N S \\
0.496-N S\end{array}$ \\
\hline
\end{tabular}

\section{Glossary to Table 4}

RA, rheumatoid arthritis; LnP, liponecrotic pancreatitis; GGT, gamma-glutamyl transpeptidase; SD, standard deviation

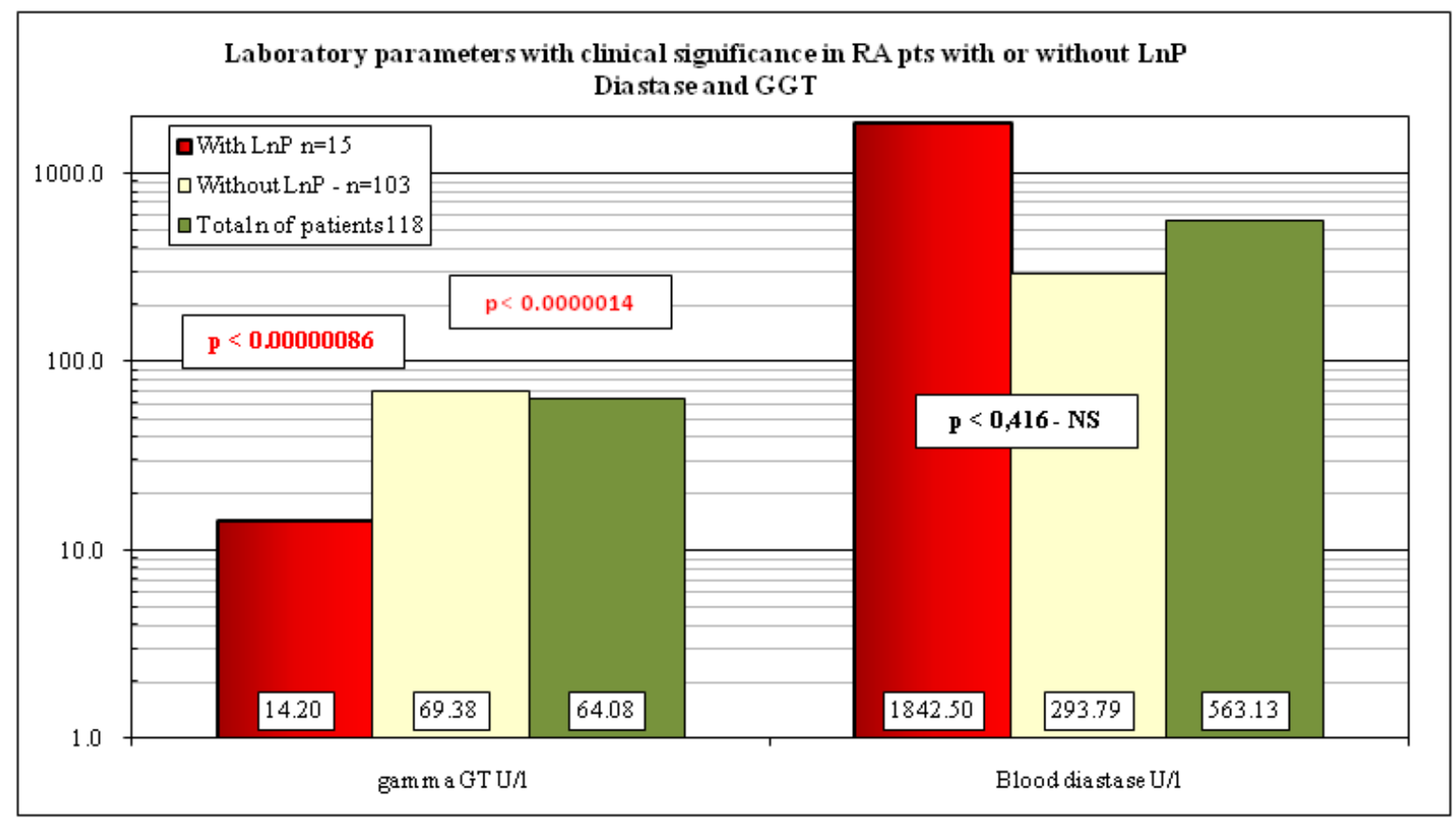

Figure 4 Significant differences in laboratory parameters with and without LnP or of total population of RA patients.

Citation: Bély M,Apáthy A. Pancreatitis in rheumatoid arthritis and the role of systemic vasculitis of autoimmune origin in the pathogenesis of pancreatitis - A postmortem clinicopathologic study of I6I patients. Gastroenterol Hepatol Open Access. 201 9; I0(I): 19-3I. DOI: I0.15406/ghoa.2019.10.0035 I 
A-SV was associated with aRelLnP in $3(20.0 \%)$ of 15 cases; A-SV was not associated with aLnP or chrLnP. The link between A-SV and LnP was positive and significant (association's coefficient $=0.7539$, $\chi^{2}=8.8418, \mathrm{p}<0.003$ ), which was resulted by the very strong positive correlation between A-SV and aRelLnP (association's coefficient $\left.=0.9736, \chi^{2}=17.6948, \mathrm{p}<0.0000\right)$. The relationship between A-SV and aLnP (association's coefficient negative: $-1, \chi^{2}=0.0231$, $\mathrm{p}<0.88$ ) or A-SV and chrLnP (association's coefficient negative: -1 , $\left.\chi^{2}=0.3570, p<0.55\right)$ was not significant.

The aLnP and aRelLnP are demonstrated in Figures 5 \& Figure 6. The acute-subacute-cubchronic-chronic stages of non-specific A-SV (Figures 7-9), in combination with fibrinoid necrosis (Figure 10), with acinar liponecrotic foci are demonstrated in Figures 10-11.

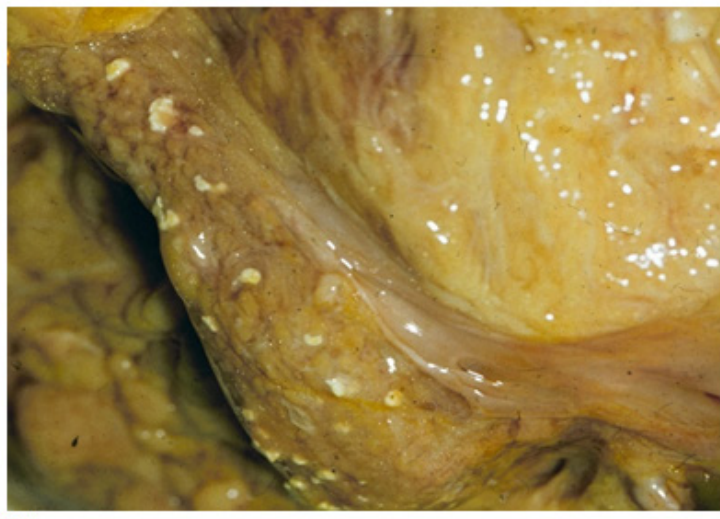

(a)

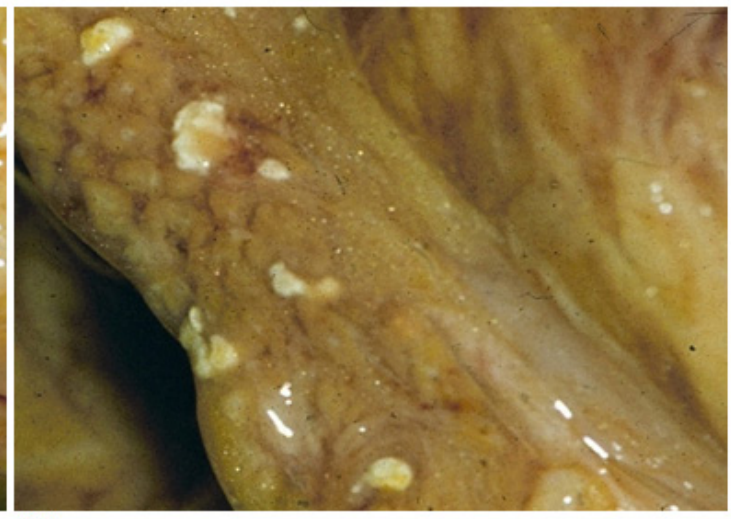

(b)

Figure 5 Acute liponecrotic pancreatitis of ductal origin - aLnP. Liponecrotic foci are present at the same stage of necrobiosis. (a) Macrophotograph $\times 1$, (b) $\times 2$.

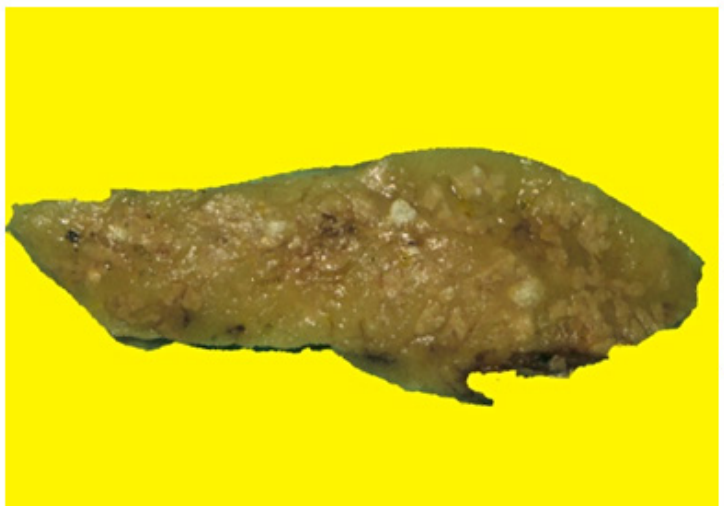

(a)

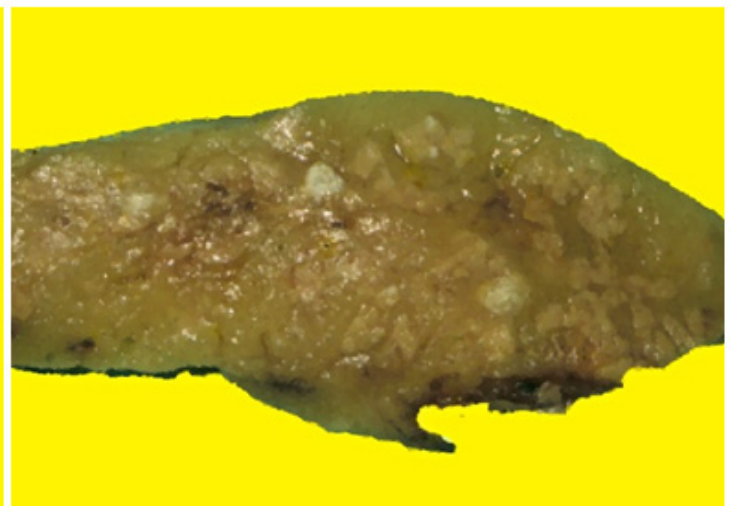

(b)

Figure 6 Acute relapsing liponecrotic pancreatitis of vasculogenic origin - aRelLnP. Liponecrotic foci of different sizes and in different stages of necrobiosis in association with SV. (a) Macrophotograph $\times 1$, (b) $\times 2$.

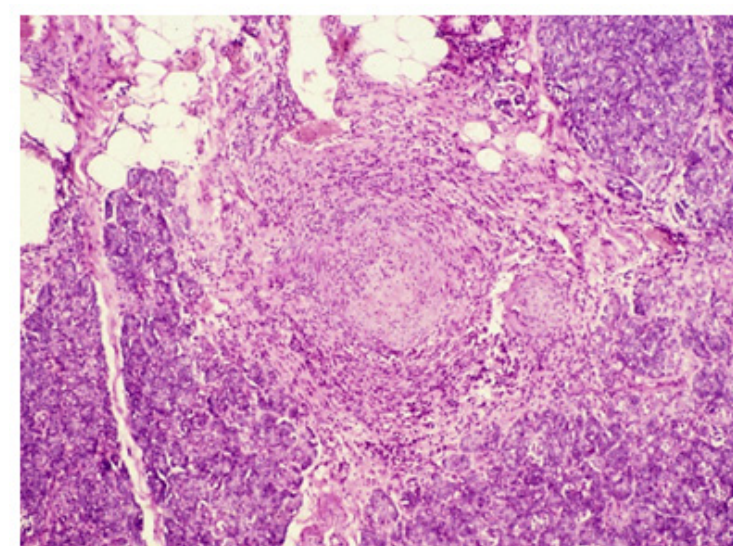

(a)

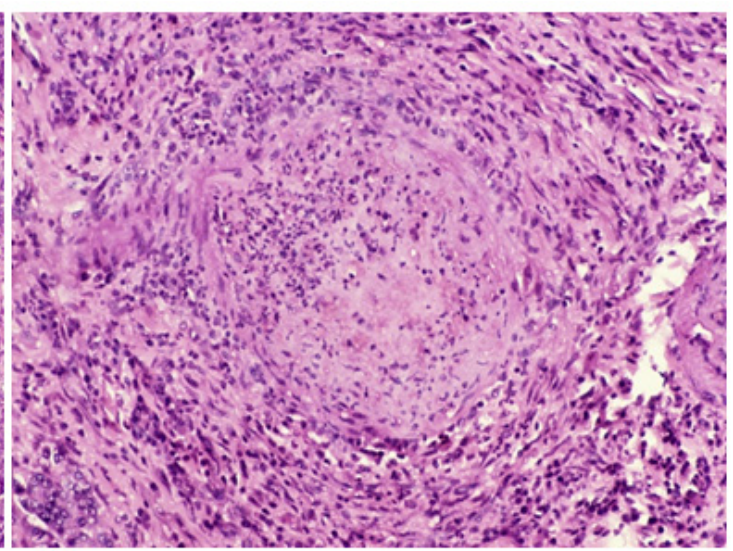

(b)

Figure 7 Rheumatoid arthritis, pancreas, arteriole. Acute non-specific thrombovasculitis. (a) Hematoxylin-Eosin staining (H-E), $x 50$, (b) same as (a) $x \mid 25$. 


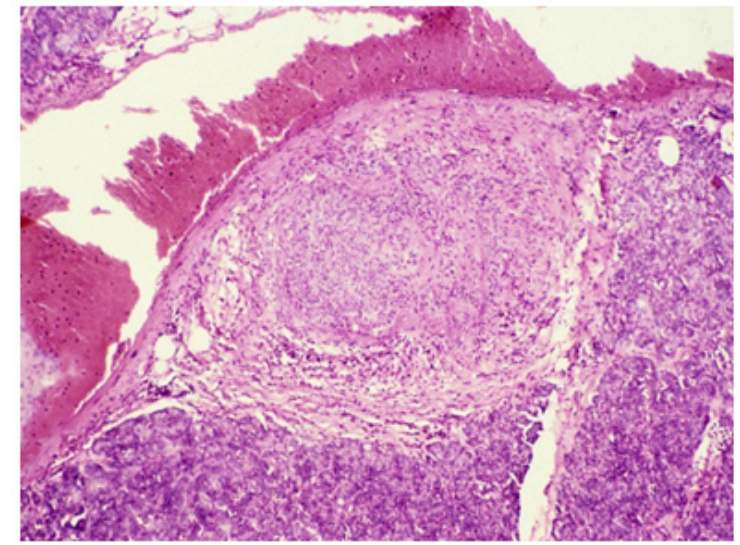

(a)

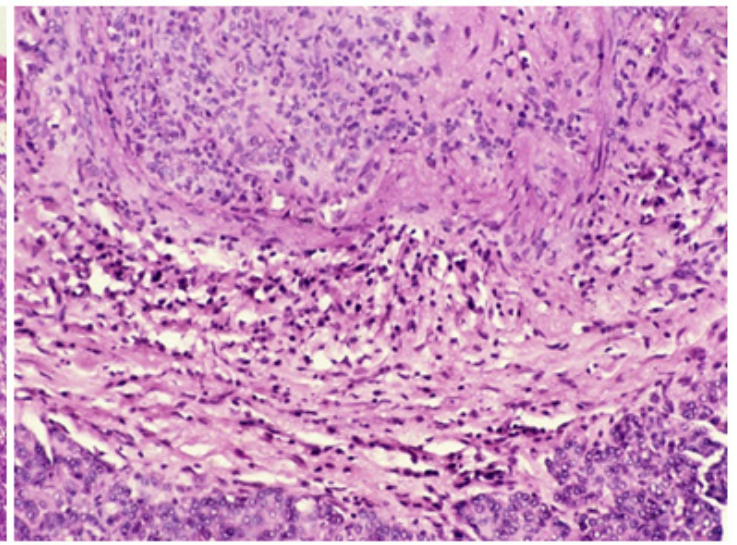

(b)

Figure 8 Rheumatoid arthritis, pancreas, arteriole, Subacute non-specific thrombovasculitis.

(a) $\mathrm{H}-\mathrm{E}, \times 50$, (b) same as (a) $\times \mathrm{I} 25$.

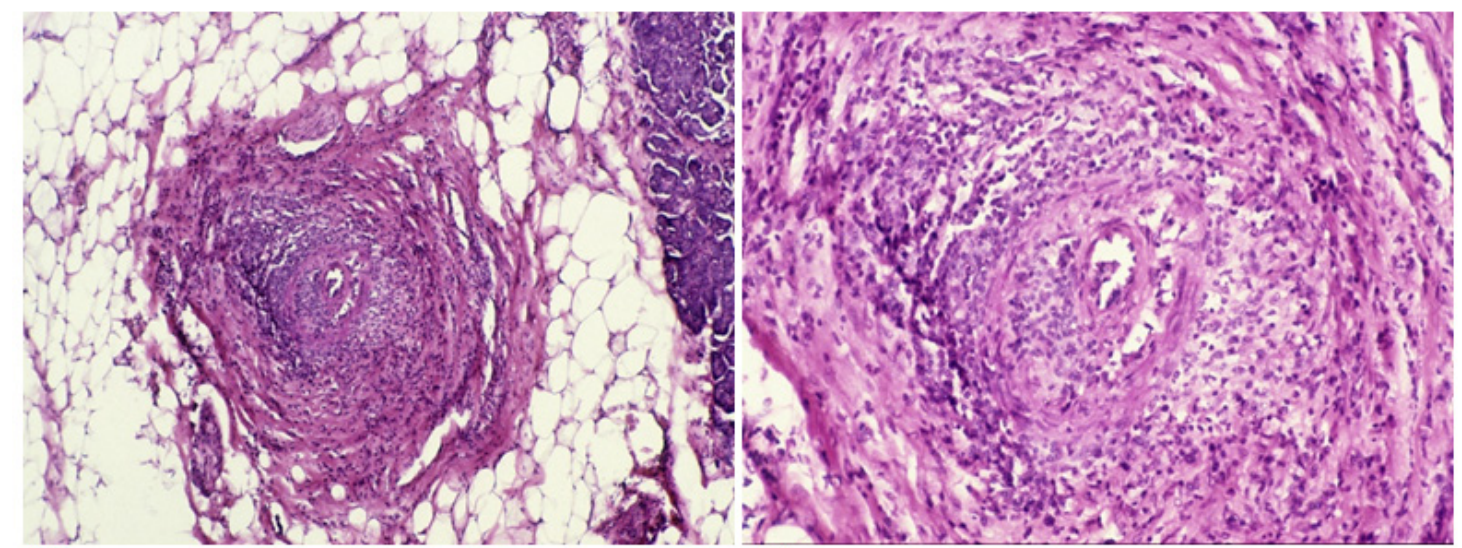

(a)

(b)

Figure 9 Rheumatoid arthritis, pancreas, small artery, Chronic non-specific vasculitis.

(a) $\mathrm{H}-\mathrm{E}, \times 50$, (b) same as (a) $\times \mathrm{I} 25$.

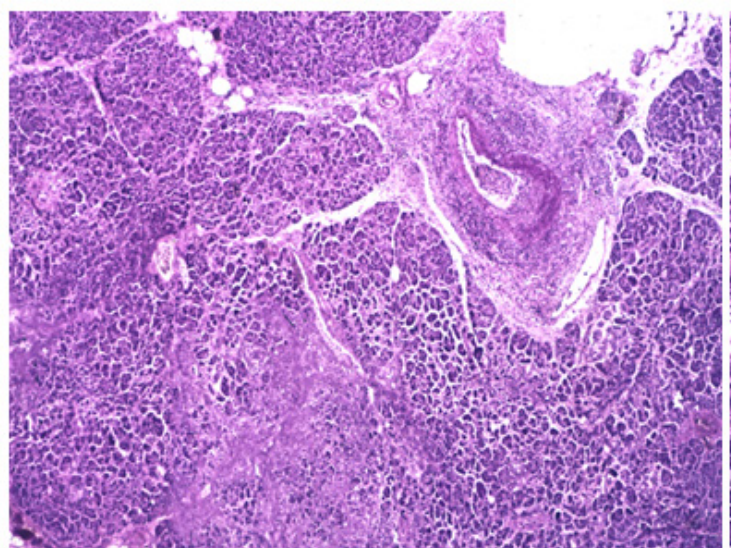

(a)

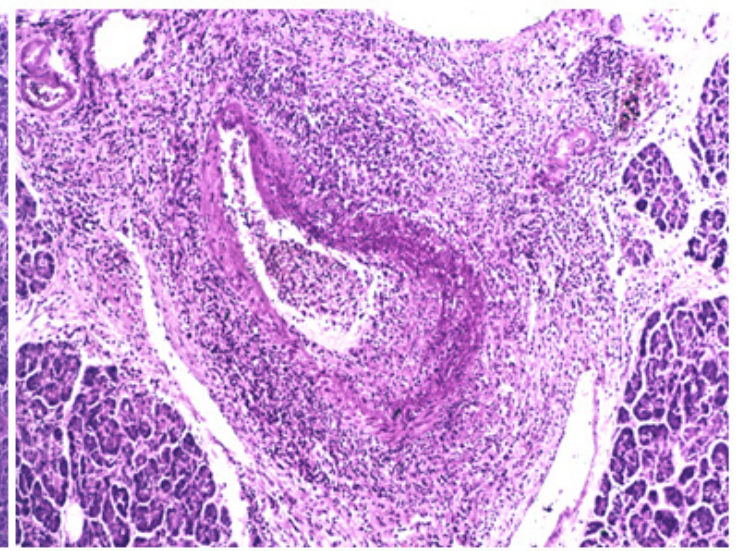

(b)

Figure 10 Rheumatoid arthritis, pancreas, small artery, Combined non-specific and fibrinoid necrotic vasculitis of autoimmune origin with incipient focal parenchymal necrosis of pancreas.

(a) $\mathrm{H}-\mathrm{E}$ and PAS combined staining, $\times 20$, (b) same as (a) $\times 50$.

(Original magnifications correspond to the $24 \times 36 \mathrm{~mm}$ size may be different, therefore it is necessary to indicate the original transparency slide - the correct height: width ratio is $2: 3$. The printed magnifications corresponding to a fixed size.) 


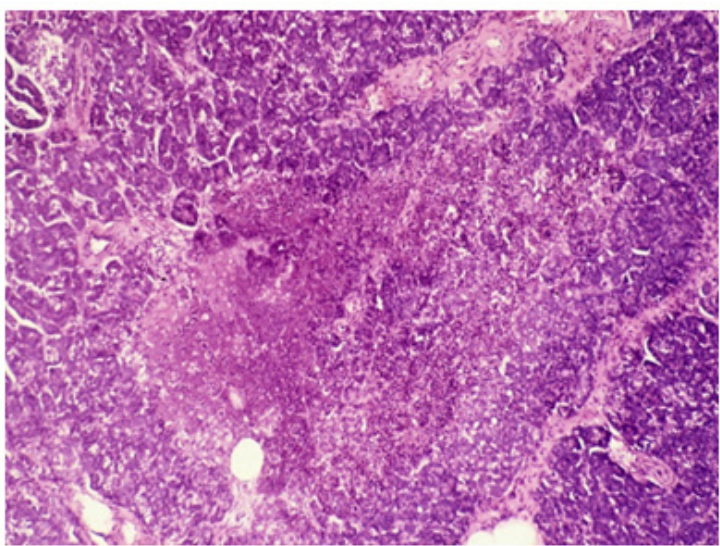

(a)

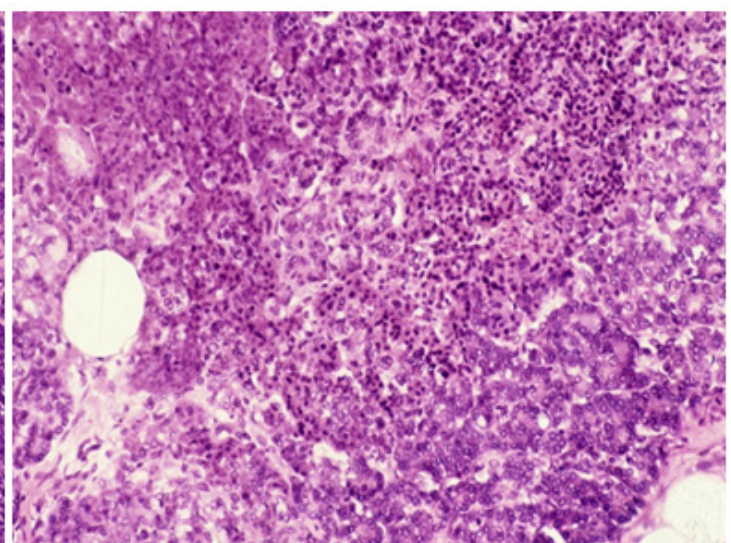

(b)

Figure I I Rheumatoid arthritis, pancreas, focal necrosis of glands with inflammatory reaction.

(a) $\mathrm{H}-\mathrm{E}, \times 50$, (b) same as (a) $\times 125$.

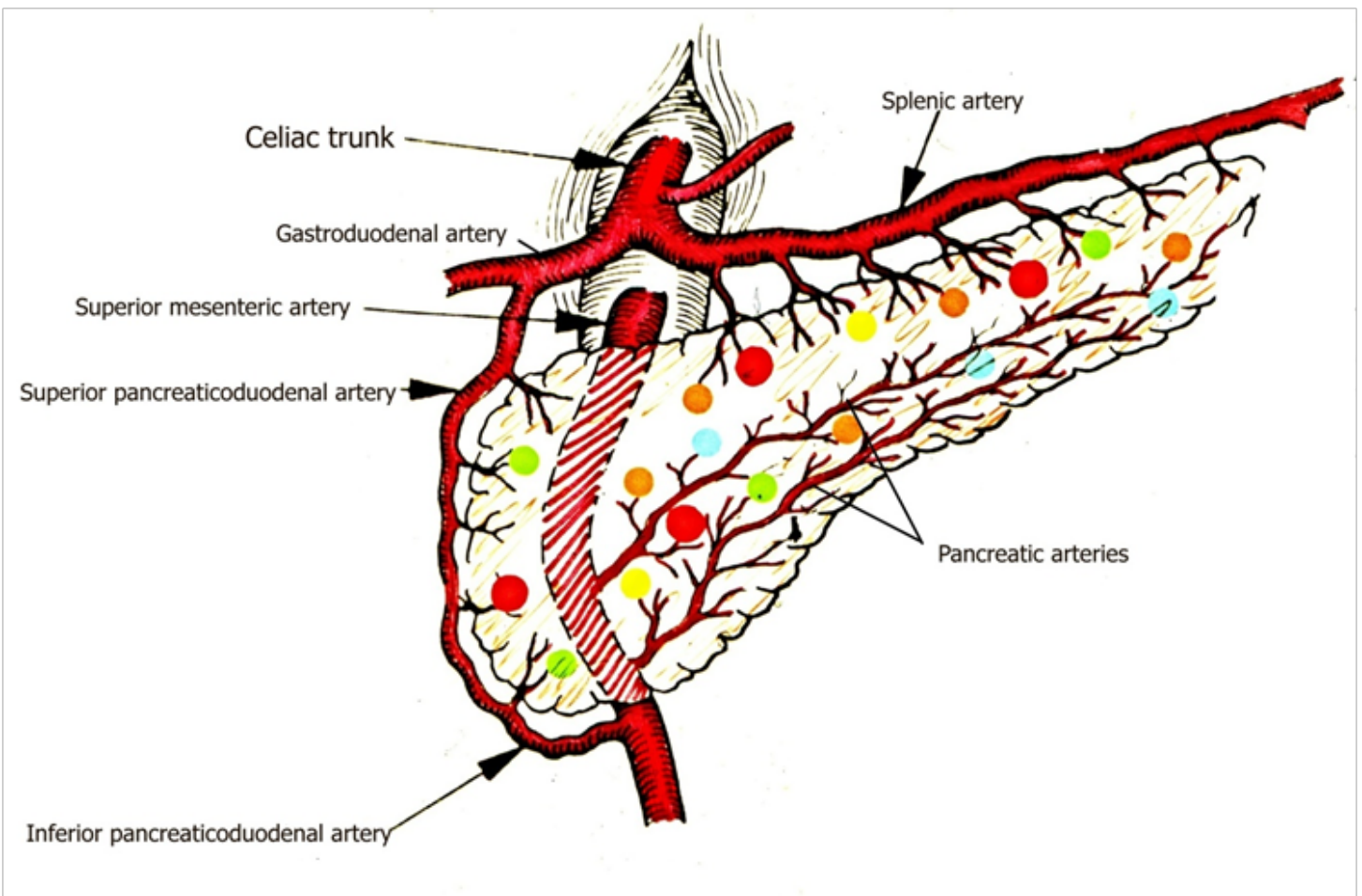

Figure 12 Schematic portrayal of anatomic backgroung or aRelLnP (different - acute-subacute-subchronic-chronic - stages of liponecrotic foci (relapsing liponecrotic pancreatitis) are demonstrated with different colours).

\section{Discussion}

The most common causes of aLnP or aRelLnP are gallstones. Trauma to the abdomen, lipid (triglyceride) disorders (hyperlipoproteinemia), hyperparathyroidism, reflux of duodenal content, and acute alcohol abuse may also have a role of in the pathogrenesis of acute pancreatitis. ${ }^{7,14}$ Certain medications (such as immunosuppressants, estrogens, thiazide diuretics, and azathioprine) can cause acute pancreatitis as well. ${ }^{7}$ The role of a vascular factor, e.g. blockage of blood vessels cannot be excluded as an etiologic factor of $\mathrm{LnP}$ as well. ${ }^{14}$ The cause of acute pancreatitis is unknown in 10 to $15 \%$ of patients and is considered idiopathic. ${ }^{7,8}$

The most important causal factor of chrP or chrRelP is chronic alcoholism ${ }^{7,8,13,14}$ but occasionally hyperparathyroidism may also be associated with chrP or chrRelP., ${ }^{2,14}$ The cause of chronic pancreatitis cannot be identified in about $25-30 \%$ of patients. ${ }^{7,8,10,11}$

Chang et al. ${ }^{1}$ concluded in their cohort study, that the patients with RA are at higher risk for acute pancreatitis compared to those without RA. ${ }^{1}$ In our study the risk of LnP or A-SV was higher in elderly female RA patients at later onst of RA (55.4 years versus 50.15 , and 60.57 years versus 48.33 resp.). Female RA patients with LnP or A-SV died earlier (within 7.44 years versus 14.93 , and 10.00 years versus 15.09 resp.) in comparison with males or with female RA patients without LnP or A-SV.

$\mathrm{A}-\mathrm{SV}$, as a basic complication of RA, should be regarded an important pathogenetic factor of $\mathrm{LnP}^{22-26}$ which was responsible for a fifth of $15 \mathrm{LnP}$ in our study. A-SV associated exclusively with 
aRelLnP only in $3(75.0 \%)$ of 4 patients, and AAa was associated with one $(25.0 \%)$. There was a very stong relationship between A-SV and aRelLnP $\left(\chi^{2}=17.6949, \mathrm{p}<0.0000\right)$. In these $4(26.66 \%)$ of $15 \mathrm{LnP}$ patients aRelLnP was considered as consequence of A-SV or AAa, and therefore were regarded as an indirect complication of RA; the rest $11(73.33 \%)$ of $15 \mathrm{LnP}$ were considered an associated disease in RA.

Vasculitis of the pancreatic arterioles and small arteries (branches of splenic artery, upper and lower gastroduodenal arteries) can lead to local ischemia and to regressive changes in the pancreatic gland. This process may be more or less widespread and multifocal, depending on the number of involved vessels. The size of necrobiotic areas is determined by the size of involved blood vessels. This vasculogenic multi- (micro-) focal necrosis of the pancreas is followed by reactive inflammation and later by fibrosis etc., depending on the stages of the pathological process. Hemorrhages, calcification (saponification) or liquefaction (pseudocyst formation) can diversify the process. Because of the recurrent nature of autoimmune vasculitis the regressive changes accumulate within the pancreas with time, and exist in different stages at death. Different sizes and stages of focal necrosis, and the co-existent vasculitis, furthermore the lack of ductal or acinar abnormalities supports the histological diagnosis of vasculogenic pancreatitis (vasculogenic origin of aRelLnP). The progressive and relapsing process in the pancreas may cause recurrent abdominal symptoms. Spontaneous remissions insidiously may lead to metabolic irregularities resistant to therapy.

The anatomic backgroung of aRelLnP caused by relapsing A-SV is presented schematically in Figure 12. Based on the strong and significant association between aRelLnP and A-SV, this form of pancreatitis may be regarded as a special manifestation of autoimmune vasculitis (a new vasculogenic entity in RA) or may be considered as a special vasculogenic type of autoimmune pancreatitis not mentioned in compilation of Mayo clinic staffs. ${ }^{27}$ Plausibly similar vasculogenic changes of the pancreas may be expected in other autoimmune diseases (such as systemic sclerosis, panarteritis nodosa, etc. as well. ${ }^{22,25}$

Signs and symptoms of pancreatitis (upper abdominal pain, fever, rapid pulse, nausea, vomiting, weight loss, etc.) may vary, depending on the type of pancreatitis. ${ }^{2}$ According to Vollertsen and $\mathrm{Conn}^{28}$ the most common laboratory findings of rheumatoid vasculitis are the elevated ESR, increased CRP level, anemia, thrombocytosis, hypoalbuminemia, and a positive rheumatoid factor. ${ }^{28}$ In Nikolaisen and coworkers' study ${ }^{29}$ the cut-off titres for rheuma factor by WaalerRose haemagglutination test was 1:160.

Laboratory values mentioned by Vollertsen and $\mathrm{Conn}^{28}$ were elevated in our patient cohort's with A-SV as well, but probable, because of the limited number of patients and/or the high values of SDs, the differences were not significant. In contrast with these we found very strong and consequent differences between our patient cohort's regarding the Latex $(p<0.0003$ and 0.0014$)$, BUN $(p<0.011$ and 0.018$)$ and creatinin $(p<0.0033$ and 0.008$)$ between patients with and without A-SV or in comparison with the total population of the patients.

In earlier studies the renal involvement has been considered unsusual in rheumatoid vasculitis, but according to several recent ones this may be more common than previously recognized. ${ }^{28}$ The higher values of BUN in comparison to normal range $(9.14 \pm 3.25$ versus 2.00 $8.90 \mathrm{mmol} / \mathrm{l})$ and the elevated creatinin level $(81.2 \pm 33.02$ versus 62 $106 \mu \mathrm{mol} / \mathrm{l})$ support the renal involvement by A-SV. The significantly lower values of BUN $(9.14 \mathrm{mmol} / \mathrm{l})$ and creatinin $(81.27 \mu \mathrm{mol} / \mathrm{l})$ with A-SV in comparison without A-SV (13.41 mmol/l and $131.42 \mu \mathrm{mol} / \mathrm{l})$ or total population of patients $(12.37 \mathrm{mmol} / \mathrm{l}$ and $119.96 \mu \mathrm{mol} / \mathrm{l})$ suggest, that the reduced renal function is caused primarily not by vasculitis. The role of amyloidosis may be more important.

The RA patients were anemic in all groups of patients in comparison to the normal laboratory range ( $4.05 \mathrm{~T} / 1$ versus $4.50-5.90$ $\mathrm{T} / 1)$. RBC values decreased in patients without A-SV (3.68 T/1) or in total population $(3.78 \mathrm{~T} / 1)$, and were lower than in patients with A-SV $(4.05 \mathrm{~T} / \mathrm{l})$ suggesting also, that not the A-SVinfluence primarily the anemia. Renal hypoxia stimulates erythropoiesis in the bone marrow by erythropoietin secreted of the kidneys, and renal hypoxia and may be related to renal amyloidosis as well.

Our study supports the clinical significance of laboratory parameters (elevated erythrocyte sedimentation rate, increased C-reactive protein level, anemia, thrombocytosis, hypoalbuminemia, and a positive rheumatoid factor) mentioned in the literature for the diagnosis of autoimmune systemic vasculitis (A-SV), but significant differences were found only regarding the Latex fixation, BUN and creatinine levels of RA patients. Unfortunately the classic clinical-laboratory parameters (mentioned in the pertinent literature and analyzed in our study (Latex, BUN, creatinine, albumin, alfa-2 globulin, CRP, Waaler-Rose, RBC, and ESR) are not specific for vasculitis and do not predict vasculitis. They are related to the basic activity of RA, to renal complications of RA or to the actual intensity of inflammatory processes of the disease.

In approximately $5-6 \%$ of the patients chronic pancreatitis is caused by autoimmune inflammation. ${ }^{7,8}$ Recognition of autoimmune vasculogenic pancreatitis belongs to the art of medicine. Clinically known autoimmune diseases and clinical suspicion of vasculitis (classic skin lesions: purpura, petechiae, deep cutaneous ulceration, peripheral gangrene, digital or nailfold infarcts), and neurological symptoms (mononeuritis multiplex, peripheral neuropathy) may help and remain the main features in suspected vasculitis, prevailing as leading indicators for its detection. ${ }^{18,30-32}$ Other causes of similar lesions (diabetes, atherosclerosis, drug reactions, infection, and neoplasm) should be excluded. ${ }^{33}$ In cases of suspected vasculitis the biopsy remains the gold standard. Because the low incidence of vasculitis in the skin $(34.78 \%)$ or the relatively rare involvement of peripheral nerves $(52.17 \%)$ we suggested the sural nerve biopsy with surrounding muscle (with $64.29 \%$ prevalence) to confirm and characterize an existing vasculitis (with or without visible involvement of the skin). ${ }^{34}$

In a cohort study of Chang et al. (2015) the administration of oral corticosteroid decreased the risk of acute pancreatitis in RA patients, ${ }^{1}$ and according to Mustak et al. (2011) the treatment of autoimmune pancreatitis combined with steroid and metothrexate may also be successful; ${ }^{35}$ presumably these medications may also be usful in the treatment of aRelLnP generated byA-SV.

\section{Conclusion}

The risk of $\mathrm{LnP}$ or A-SV is higher in elderly female RA patients, and their chance of survival is lower than in males, or compared with RA patients who did not have LnP or A-SV. A-SV, as a basic complication of RA, should be regarded an important vasculogenic factor in the pathogenesis of aRelLnP, which may be regarded as a special manifestation of autoimmune pancreatitis or a vasculogenic entity in RA. 
Our study supports the clinical significance of laboratory parameters (elevated erythrocyte sedimentation rate, increased C-reactive protein level, anemia, thrombocytosis, hypoalbuminemia, and a positive rheumatoid factor) mentioned in the literature for diagnosis of A-SV, but significant differences were found only regarding the Latex fixation, BUN and creatinin levels of RA patients. Unfortunately the classic clinical-laboratory parameters (mentioned in the pertinent literature and analyzed in our study (Latex, BUN, creatinine, albumin, alfa-2 globulin, CRP, Waaler-Rose, RBC, and ESR) are not specific for vasculitis and do not predict vasculitis. They are related to the basic activity of RA, to renal complications of RA or to the actual intensity of inflammatory processes of the disease.

Elevated diastase values were characteristics for LnP, and GGT levels showed significant differences between patients with and without $\mathrm{LnP}$ or in comparison to total population. The study is recommended to general physicians, who may meet patients with autoimmune disorders or are interested in autoimmune diseases.

\section{Acknowledgments}

None.

\section{Conflicts of interest}

The author declares no conflicts of interest.

\section{References}

1. Chang CC, Chiou CS, Lin HL, et al. Increased Risk of Acute Pancreatitis in Patients with Rheumatoid Arthritis: A Population-Based Cohort Study. PLoS One. 2015;10(8):e0135187.

2. By Mayo Clinic Staff: Symptomes of pancreatitis.

3. Talamini G, Bassi C, Falconi M, et al. Alcohol and smoking as risk factors in chronic pancreatitis and pancreatic cancer. Dig Dis Sci. 1999;44(7):1303-1311.

4. FreemanML, DiSario JA, Nelson DB, et al. Risk factors for post-ERCP pancreatitis: a prospective, multicenter study. Gastrointest endosc. 2001;54(4):425-434.

5. Cheng CL, Sherman S, Watkins JL, et al. Risk factors for post-ERCP pancreatitis: A prospective multicenter study. Am J Gastroenterol. 2006;101(1):139-147.

6. Masci E, Mariani A, Curioni S, et al. Risk factors for pancreatitis following endoscopic retrograde cholangiopancreatography: a metaanalysis. Endoscopy. 2003;35(10):830-834.

7. By Columbia University Staff: Causes of Pancreatitis. Columbia University Department of Surgery. columbiasurgery.org/pancreas/ causes-pancreatitis

8. Finkelberg DL, Sahani D, Deshpande V, et al. Autoimmune Pancreatitis. N Engl J Med. 2006;355:2670-2676.

9. Etemad B, Whitcomb DC. Chronic pancreatitis: diagnosis, classification, and new genetic developments. Gastroenterology. 2001;120(3):682-707.

10. Pham A, Forsmark C. Chronic pancreatitis: review and update of etiology, risk factors, and management. F1000 Research, 2018;Faculty Rev-607.

11. Sankaran SJ, Xiao AY, Wu LM, et al. Frequency of progression from acute to chronic pancreatitis and risk factors: a meta-analysis. Gastroenterology. 2015;149(6):1490-1500.e1.

12. Ahmed AU, Issa Y, Hagenaars JC, et al. Risk of Recurrent Pancreatitis and Progression to Chronic Pancreatitis After a First Episode of Acute Pancreatitis. Clin Gastroenterol Hepatol. 2016;14(5):738-746.
13. Scarpelli DG. Acute pancreatitis and Chronic pancreatitis . Lippincott Company, Philadelphia, London, Mexico City, New York, St. Louis, Sao Paulo, Sydney. In: Rubin E, Farber JL, editors. Pathology. 1988, ch. 15, p. 812-816 and 816 .

14. Zollinger HU. Acute pancreatitis and Chronic pancreatitis. Georg Thieme Verlag, Stuttgart, New York. In Zollinger HU, editor. Pathologische Anatomie. 1981, Band I Allgemeine Pathologie, p. 64-66.

15. Bély M, Apáthy Á. Clinical pathology of rheumatoid arthritis: Cause of death, lethal complications and associated diseases in rheumatoid arthritis. First English edition, Akadémiai Kiadó, Budapest, 2012, 1-440.

16. Arnett FC, Edworthy SM, Bloch DA, et al. The American Rheumatism Association 1987 revised criteria for the classification of rheumatoid arthritis. Arthritis and Rheumatism, 1988;31:315-324.

17. Jennette JC, Falk RJ, Bacon PA, et al. 2012 Revised International Chapel Hill Consensus Conference Nomenclature of Vasculitides. Arthritis Rheum. 2013;65(1):1-11.

18. Scott DGI, Bacon PA, Tribe CR. Systemic Rheumatoid Vasculitis: A Clinical and Laboratory Study of 50 Cases. Medicine (Printed in USA). 1981;60(4):288-297.

19. Schilling F, Fassbender HG. Entzündliche Gefäßveränderungen (Vaskulitiden), insbesondere bei chronischer Polyarthritis (rheumatoide Vaskulitis)" in Angiologie and Hämostaseologie. Gustav Fischer, Stuttgart, New York. In: Breddin K, Gross D, Rieger H, editors 1988 , pp. 94-118.

20. Lentner C. Statistical methods. In: Lentner C, Diem K, Seldrup J, editors. Geigy scientific tables $8^{\text {th }}$ revised and enlarged. Ciba-Geigy Limited, Basle, Switzerland, 1982, Volume 2, p. 227.

21. Szentágothai J, Réthelyi M, Verőerek Visszerek. Funkcionális anatómia II. Medicina, Budapest, 2002, pp. 770-786, 786-788

22. Bély M, Apáthy Á. Systemic Vasculitis in Progressive Systemic Sclerosis: Clinicopathological correlation with complex nephropathy, cardiomyopathy and microfocal pancreatitis - A retrospective study of 11 autopsy patients. Annals of the Rheumatic Disease. 2002;61(Suppl 1): 115 .

23. Bély M, Apáthy Á. Pancreatic arteritis and vasculogenic reurrent pancreatitis in rheumatoid arthritis - A retrospective clinicopathologic study of 161 autopsy patients. Annals of the Rheumatic Disease. 2002;61(Suppl 1):399.

24. Bély M, Apáthy A. Recurrent pancreatic arteritis and vasculogenic relapsing pancreatitis in rheumatoid arthritis-a retrospective clinicopathologic and immunohistochemical study of 161 autopsy patients. Pathol Oncol Res. 2008;14(4):473-480.

25. Bély M, Apáthy Á. AB0240 Prevalence and severity of systemic vasculitis in various organs of patients with progressive systemic sclerosis. Annals of the Rheumatic Diseases. 2013;71:651

26. Apáthy Á, Bély M. SAT0120 Multifocal recurrent pancreatitis caused by systemic secondary AA amyloidosis in rheumatoid arthritis - a postmortem clinicopathologic study of 161 patients. Annals of the Rheumatic Diseases. 2018;77:922.

27. By Mayo Clinic Staff: Autoimmune pancreatitis.

28. Vollertsen RS, Conn DL. Vasculitis associated with rheumatoid arthritis. Rheum Dis Clin North Am. 1990;16(2):445-461.

29. Nikolaisen C, Rekvig OP, Nossent HC. Rheumatoid factor by laser nephelometry and Waaler-Rose assay: prognostic value in patients with recent-onset rheumatoid arthritis. Scand J Rheumatol. 2005;34(4):269276.

30. Ntatsaki E, Mooney J, Scott DGI, et al. Systemic rheumatoid vasculitis in the era of modern immunosuppressive therapy. Rheumatology. 2014;53(1):145-152. 
31. Makol A, Crowson CS, Wetter DA, et al. Vasculitis associated with rheumatoid arthritis: a case-control study. Rheumatology (Oxford). 2014;53(5):890-899.

32. Saljoughian M. Rheumatoid Vasculitis: A Complication of Rheumatoid Arthritis. US Pharmscist. 2018;43(6):26-28.

33. Schmid FR, Cooper NS, Ziff M, et al. Arteritis in rheumatoid arthritis. American Journal of Medicine. 1961;30(1):56-83.
34. Bély M, Apáthy Á. Diagnosis of Systemic Vasculitis of Autoimmune Origin in Rheumatoid Arthritis: Biopsy of Skeletal Muscle in Combination with Sural Nerve is Optimal - A Postmortem Clinicopathologic Study of 161 Patients. EC Cardiology. 2018;5(1):17-25.

35. Mustak M, Boltuch-Sherif J, Horvath-Mechtler B, et al. Autoimmune pancreatitis associated with rheumatoid arthritis: successful combination therapy with steroids and methotrexate. Dtsch Med Wochenschr. 2011;136(37):1842-1844. 